\title{
Dietary diversity, environment and health-related factors of under-five children: evidence from cassava commercialization households in rural South-West Nigeria
}

\author{
Olutosin Ademola Otekunrin ${ }^{1}$ (D) Oluwaseun Aramide Otekunrin ${ }^{2} \cdot$ Idris Akanbi Ayinde ${ }^{1}$. \\ Rahman Akintayo Sanusi ${ }^{1}$. Oluseye Olusegun Onabanjo ${ }^{3}$. Oluwaseun Ariyo ${ }^{4}$
}

Received: 9 August 2021 / Accepted: 22 October 2021 / Published online: 30 October 2021

(c) The Author(s), under exclusive licence to Springer-Verlag GmbH Germany, part of Springer Nature 2021

\begin{abstract}
Diverse and quality diets are crucial to sustainable growth and development of under-five children, especially those of rural farming households. This study investigated the dietary diversity, environment, and health-related factors of young children. The study employed the use of cross-sectional survey data from 140 under-five children of cassava farming households in Ogun and Oyo states, South-West Nigeria. The study estimated factors influencing dietary diversity of under-five children and assessed children dietary diversity, and the availability of some environment and health-related factors of the farming households. The findings indicated that $98.7 \%$ and $97.5 \%$ of children consumed grains, with roots and tubers while $36.7 \%$ and $36.3 \%$ consumed legumes in Ogun and Oyo states respectively. The results also found that $48.6 \%$ of children sampled met the minimum cut-off point of 4 food groups with dietary diversity mean score of 3.28. The logit regression analysis indicated that child's age, mothers' age, distance to farm, and food expenditure were among the significant determinants of children dietary diversity. Therefore, this study seeks the collaborative efforts of stakeholders in providing nutrition-sensitive intervention programs for household members, especially mothers and young children in order to promote consumption of diversified diets and enhance healthy living of rural farming households.
\end{abstract}

Keywords Under-five children · Children dietary diversity score (CDDS) $\cdot$ Malnutrition · Diverse diets · Farm households . Sustainable development goals

\section{Introduction}

Diversity of infants and young children's diet is of utmost importance in ensuring sustainable growth and development from infancy to adulthood. When diets are not diversified,

Responsible Editor: Lotfi Aleya

Olutosin Ademola Otekunrin

otekunrin.olutosina@pg.funaab.edu.ng;

otekunrinolutosin@yahoo.com

Oluwaseun Aramide Otekunrin seramide2003@yahoo.co.uk

Idris Akanbi Ayinde idrisayinde@gmail.com

Rahman Akintayo Sanusi sanusira@funaab.edu.ng

Oluseye Olusegun Onabanjo onabanjooo@funaab.edu.ng

Oluwaseun Ariyo

ariyoseun@gmail.com
1 Department of Agricultural Economics and Farm Management, Federal University of Agriculture, Abeokuta (FUNAAB), Nigeria

2 Department of Statistics, University of Ibadan, Ibadan, Nigeria

3 Department of Nutrition and Dietetics, Federal University of Agriculture, Abeokuta (FUNAAB), Nigeria

4 Department of Human Nutrition, University of Ibadan, Ibadan, Nigeria 
young children are exposed to divers forms of malnutrition (undernutrition or overnutrition), mostly stunting and micronutrient deficiency, and leading to heightened morbidity and mortality (NPC and ICF 2019). Young children and women of child-bearing age are mostly regarded as the major groups of people at risk of burdens of malnutrition and therefore, high-quality diets are recommended for them to meet their daily dietary requirement (Global Panel 2016; Garnett 2016; Otekunrin et al. 2019a, b; Otekunrin and Otekunrin 2021a). Diverse and quality diets are equally pivotal to the nutrition and healthy living of all members of the household. Issues of diet and diet quality are crucial to the attainment of almost all the United Nations Sustainable Goals. The most prominent SDGs are SDGs 2, 3, and 12; "end hunger," "ensure healthy and promote wellbeing for all at all ages" and "ensure sustainable consumption and production patterns" respectively (UNGA 2015; EUPHA 2017; Otekunrin and Otekunrin 2021b). Dietary pattern is regarded as a health barometer and as an indicator of the value of the diets consumed. It is equally valuable for measuring food security status of a particular population (Mirmiran et al. 2006; Azadbahkt and Esmailzader 2012; Obayelu and Osho 2020). Dietary diversity is usually linked to the value and amount of food, usually in terms of its accessibility, availability, affordability, and utilization to meet members of the household's nutrition recommendations (Hilbruner and Egan 2008; Kennedy et al. 2010; Obayelu and Osho 2020). Highquality and diverse diet is sufficient with regards to value and amount, inexpensive, harmless, and culturally acceptable, while contributing to human nutrition and health status (Drewnowski 2014; Donati et al. 2016; Fanzo 2019; FAO et al. 2020; Otekunrin and Otekunrin 2021b). Dietary diversity complements the consumption of all-important dietary fibers and antioxidants that help to ward off diseases (Johns and Eyzaguirre 2007; WHO 2013; Akerele et al. 2017).

The reports from Nigeria Demographic and Health Survey (NDHS) 2018 showed that $37 \%$ of under-five children are stunted, $7 \%$ are wasted, and $22 \%$ are underweight. The report also showed that a little above $10 \%$ of under 24 -month children were fed minimum acceptable diets in the 24-h period before the commencement of the survey. It is worthy of note that $38.9 \%, 58.4 \%$, and $39.1 \%$ of the rural households in Nigeria had access to electricity, good source of drinking water, and improved toilet facilities respectively (NPC and ICF 2019). However, empirical reports also revealed that the proportion of undernourished population in Nigeria moved up from about $10 \%$ in 2000 to $14 \%$ in 2018 (von Grebmer et al. 2019; Otekunrin et al. 2020a; Ayinde et al. 2020; Otekunrin 2021). Studies by International Food Policy Research Institute (IFPRI) reported that most of the undernourished population in developing countries are members of smallholder farming households especially in developing low- and middle-income countries who depend mainly on agriculture as significant means of livelihood with almost no social support interventions (IFPRI 2016). Quality diets are pivotal to the achievement of United Nations Sustainable Development Goal (SDG) because inadequately nourished citizens will be less innovative and productive (Garnett 2016, 2017; Willett et al. 2019; Otekunrin and Otekunrin 2021b).

High-quality dietary patterns that enhance healthy living of members of farming households are one of the factors that lead to increased agricultural production, sales of produce (crop commercialization), and by extension, to the country's food sufficiency approach.

However, the emergence of ravaging COVID-19 pandemic has huge negative effect on the diet quality of many people around the world leading to a sharp rise in the cost of food items, making it less affordable especially in the developing countries (FAO et al. 2020, 2021; Otekunrin et al. 2020a, b; Otekunrin et al. 2021; Otekunrin and Otekunrin 2020).

Agricultural commercialization (sometimes referred to as market participation) arises when agricultural operations depend mostly on the market for the sale of produce and for the purchase of production inputs (APRA 2018). Also, agricultural commercialization implies increased market transactions (that is, market participation) for capturing the gains from specialization (Carletto et al. 2017; Opondo et al. 2017; Otekunrin et al. 2019c). Commercialization comes in different ways. It may be on the output side of production regarding the sales of agricultural produce or on the input side of production pertaining to the use of purchased inputs. The measurement of the degree of commercialization of subsistence agriculture from the output side of production provides avenue to capture the marketing behavior (from pure subsistence to completely commercialize) of individual households (Carletto et al. 2017; Otekunrin et al. 2019c).

In Nigeria, cassava (Manihot esculenta Crantz) ranked first among the most important crops by production and second by consumption (SAHEL 2016; Otekunrin and Sawicka 2019). It is widely believed to be one of the most commonly cultivated root crop and likewise a food security crop in the tropical region. According to FAO statistical database, Nigeria remained the top producer of cassava in six decades (1961-2019) in Africa and globally with total production estimate of 780,000 tonnes in 1961 and now increased to $59,193,708$ tonnes in 2019, having $19.5 \%$ share of the global production (FAOSTAT 2021). About $90 \%$ of the cassava roots are consumed as food while $10 \%$ is used for industrial purposes but it is quite unfortunate that export opportunity for cassava in Nigeria is less than $1 \%$ (Otekunrin and Sawicka, 2019; Otekunrin and Otekunrin 2021a).

Previous empirical studies have reported the influence of agricultural commercialization on poverty status of rural household members (Hussayn et al. 2020), and influence 
of agricultural commercialization on nutrition outcomes of young children in Nigeria and three other developing countries (Okezie and Nwosu 2007; Carletto et al. 2017). Some studies found that about $50 \%$ of under-five children from rural households in Madagascar had poorly diversified diets (Rakotonirainy et al. 2018). Recent empirical studies that analyzed the dietary diversity of under-five children of commercializing households in Nigeria are limited. This study is therefore, contributing to existing literature by analyzing the dietary diversity, environment, and health-related factors of under-five children of cassava commercializing households in South-West Nigeria.

\section{Research methodology}

\section{The study area}

South-West is one of the six geopolitical zones of Nigeria and is located in Western region of Africa with total land mass of $923,768 \mathrm{~km}^{2}$ (Maps of World 2021). Nigeria is a multi-ethnic country having Igbo, Hausa, and Yoruba as the three major ethnic groups. The six states in South-West are; Lagos, Ekiti, Ogun, Ondo, Osun, and Oyo. The region lies between latitude $9^{\circ} 4.9199^{1} \mathrm{~N}$ and longitude $8^{\circ} 4.9199^{1} \mathrm{E}$ (Find Lattitude and Longitude 2021). Ogun state has its capital in Abeokuta which is the most populous city in the state. Ogun state lies between latitude $\mathrm{N} 6^{\circ} 54.59^{1}$ and longitude $\mathrm{E}$ $3^{\circ} 15.5018^{1}$, and covers an area of $16,980.55 \mathrm{~km}^{2}$. The state is predominantly covered by rainforest with wooden savanna in the northwest. Oyo state lies between latitude $\mathrm{N} 8^{\circ} 7.174^{1}$ and longitude E $3^{\circ} 25.1732^{1}$ and is the fifth most populous state in Nigeria with its capital in Ibadan and covers an area of $24,454 \mathrm{~km}^{2}$ (Find Lattitude and Longitude 2021). The two states are largely Yoruba speaking states, though not without diversity in dialects within and across the two states. There are two distinct seasons in Ogun and Oyo, i.e., rainy and the dry seasons. Agriculture remained the most common means of livelihood of about $70 \%$ of the rural population in Ogun and Oyo states (Lawal and Samuel, 2010; Otekunrin and Otekunrin 2021a). The main cash crops mostly grown in the Ogun and Oyo states include cocoa, citrus, and timber, while the food crops are cassava, yam, maize, cowpea, melon, and millet. Livestock production include pigs, rabbits, sheep, goats, poultry, and snails (Lawal and Samuel, 2010; Otekunrin and Otekunrin 2021a) (Fig. 1).

\section{Study design, samples, data source, and sampling procedure}

Cross-sectional data was collected and were used for this study. Multi-stage sampling procedure was employed, random sampling of two from six cassava producing states in the South-West region was done in the first stage while second stage involved random selection of five Local Government area (LGAs) from Oyo state and three LGAs from Ogun state. In third stage, 24 villages were selected from the eight LGAs. Fourth stage involved a random selection of 16 cassava farming households resulting in a total of 384 farming households. The data were gathered through structured, interviewer-administered questionnaire which include the household socioeconomic characteristics, children dietary diversity score (CDDS), environment and health-related factors, food consumption and expenditure pattern, and other salient household information. After data cleaning, 32 of the questionnaires were discarded due to incomplete information. In the 352 sampled cassava farming households, there were 140 under-five children.

\section{Modeling agricultural commercialization levels}

The cassava commercialization levels of the cassava farming households (living with the 140 under-five children) in the study areas were analyzed using crop commercialization Index (CCI) by Strasberg et al. 1999; Carletto et al. 2017; Otekunrin et al. 2019c defined as follows:

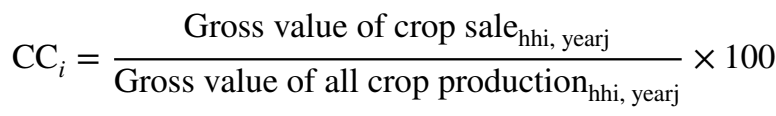

We have $h h_{i}$ is the $i^{\text {th }}$ household in year $j$.

With this method of estimation, agricultural commercialization can be represented by a scale from absolute subsistence household $(\mathrm{CCI}=0)$ to perfectly commercialized $(\mathrm{CCI}=100)$. This method allows for more than just the usual dicotomy of sellers and non-sellers, or between staple and cash crop producers (Carletto et al. 2017; Otekunrin et al. 2019c; Otekunrin and Otekunrin 2021b). It also gives information about how much of the harvested households decide to offer for sale in the market. The crop sold ratio represents the ratio of gross value of crop sold and gross value of all crop production (Shively and Sununtnasuk 2015).

Cassava farming households were categorized based on their cassava commercialization levels. Farming households that did not participate (non-sellers) in the sale of the cassava roots were categorized as follows:

(i) Zero commercialization level (CCI I=0\%) while those that participated actively (sellers) are grouped into;

(ii) Low commercialization level (CCI II = 1-49\%)

(iii) Medium-High commercialization level (CCI $\mathrm{III}=50-75 \%)$ and

(iv) Very high commercialization level (CCI IV $=>75 \%)$ levels (Otekunrin and Otekunrin 2021a) 


\section{Measuring under-five children dietary diversity score}

The under-five CDDS is an important child-centered dietary diversity questionnaire used in measuring children dietary pattern in a period of time such as 30-day, 7-day, and 24-h recall period. Seven (7) food groups and a cut-off of 4 food groups out of the seven, based on WHO guideline was adapted in this study. The food groups are as follows:

(i) Grains, white roots and tubers

(ii) Legumes, nuts and seeds

(iii) Dairy products (milk, yogurt, cheese)

(iv) Flesh foods (meat, fish, poultry and liver/organ meats, sea foods),

(v) Eggs

(vi) Vitamin A-rich fruits and vegetables

(vii) Other fruits and vegetables (WHO 2007)

The CDDS is the number of food groups consumed by the child in 24-h period. The CDDS was summed up and a score of 1 was given to each food group consumed making a maximum value of 7 points. The proportion of children achieving the minimum of 4 food groups out of 7 was calculated. Other studies that have used similar food groups include; Steyn et al. 2006; Kennedy et al. 2010; Steyn et al. 2014; Ochieng et al. 2017.A CDDS of 4 is referred to as the minimum DDS. This shows that a child having less than 4 CDDS is categorized as having low dietary diversity (WHO 2007; Rakotonirainy et al. 2018; Custodio et al. 2019).

\section{Modeling the determinants of under-five children dietary diversity}

The factors influencing dietary diversity among under-five children of cassava commercializing households were analyzed using the logistic regression model. The application of the regression modeling is appropriate given that the dependent variable which is the under-five children dietary diversity score (dichotomous in nature) grouped as one (1) if a child attains 4 or more food groups out of 7 , and zero (0) otherwise expressed as a function of a vector of independent variables hypothesized to influence the dietary diversity of under-five children of cassava commercialization households. The independent variables included in the model include child age, child gender, mothers' age, mothers' year of schooling, household size, farm size, farm income, nonfarm income, distance to market, food expenditure, mothers' nutrition knowledge, access to healthcare, access to electricity, and access to improved toilet and crop sold ratio (proxy for commercialization levels). The model specification of the logit regression is given below (Gujarati and Porter 2009):
Logit $(p)=\ln \left(\frac{p}{1-p}\right)=\beta_{0}+\beta_{i} X_{i}+U_{i}$

where $p$ denotes the probability of attaining the dietary diversity of 4 or more food groups out of 7 , the $\beta_{i}^{\prime} s$ are the parameter estimates of the independent variables, the $X_{i}^{\prime} s$ represent the independent variables and $U_{i}^{\prime} s$ are the stochastic error terms.

\section{Results and discussion}

The socioeconomic description of under-five children of cassava farming households and CDDS are presented in Tables 1 and 2. The results indicated that the mean age of the children was estimated to be 32.8 months and about $46 \%$ were male. About $73 \%$ of the household heads were men while the mean age of household head was 49 years, showing that household heads are advanced in age.

The mean household size was 6 persons while household head had about 7 years of education. The mothers had about 5 years of education. Table 1 also revealed that mean household farm income and non-farm income was N139, 250 (431 US \$, February 2020) and N66, 250 (205 US \$, February 2020) per year respectively. The mean household monthly food expenditure was N21, 892. The under-five children mean DDS (standard deviation in parenthesis) was $3.28( \pm 1.28)$ indicating that that on the average, the children fail to meet up with the WHO recommended 4 food groups out of 7 among smallholder cassava farming households in the study areas.

In Table 2, the result revealed that $96.7 \%$ and $97.5 \%$ of the under-five children consumed grains, with roots and tubers while only $36.7 \%$ and $36.3 \%$ consumed legumes in Ogun and Oyo respectively (Fig. 2). The results further indicated that only $5.0 \%$ and $13.8 \%$ of under-fives consumed dairy products in Ogun and Oyo states respectively. On the average (pooled), only $5.0 \%$ of the group consumed eggs, only $48.6 \%$ met the cut-off point of 4 food groups in 24-h recall period. Studies by Ekesa et al. (2011), Kennedy et al. (2017) and Custodio et al. (2019) found low consumption of food items such as egg, meat, and milk products among young children in some African countries.

In general, the mean number of food groups for this category was $3.28( \pm 1.28)$ indicating that the children in the study areas did not meet the recommended DDS of 4 out of 7 food groups in 24-h recall period. Other study in Nigeria recorded a mean DDS of 6.04 out of 12 food groups for under-five children in Imo state (Ukegbu and Ogu 2017). Studies from other developing economies like the Philippines and Trinidad and Tobago where a mean DDS of 4.91 from 9 food groups for young children in the Philippines while 4.6 from 6 food groups was recorded for under-five 
Table 1 Description of household and child-related factors

\begin{tabular}{llll}
\hline Variables & Description & Mean & Standard deviation \\
\hline Child's age & Under-five child's age (months) & 32.82 & 17.49 \\
Household size & Number of persons belonging to the household & 5.84 & 2.28 \\
Household head's age & Head of household's age (years) & 49.57 & 10.94 \\
Mother's age & Age of child's mother (years) & 39.49 & 9.62 \\
Household head education & Number of years of schooling of household head & 6.99 & 3.97 \\
Mother's education & Number of years of schooling of child's mother & 4.89 & 3.78 \\
DDS & Dietary diversity score of under-five (0-7) & 3.28 & 1.28 \\
Farm size & Size of the household cassava farmland (hectare) & 1.41 & 0.99 \\
Farm income & Total household farm income annually (naira) & 139,250 & 120,669 \\
Non-farm income & Annual household non-farm income (naira) & 66,250 & 64,641 \\
Food expenditure & Household food expenditure (monthly) & 21,892 & 8,824 \\
Distance to market & Distance from farm to closest market (Km) & 9.15 & 4.39 \\
Crop share ratio & Crop commercialization index (CCI) level & 0.6262 & 0.2808 \\
\hline
\end{tabular}

Source: underlying survey data 2020. Exchange rate in February 2020: 1 US \$=N323 Number of under-five children=140.

Table 2 CDDS (under-five) of cassava farming household members' food groups

\begin{tabular}{lllll}
\hline S/N & Food groups & $\begin{array}{l}\text { Ogun }(n=60) \\
\text { Frequency }(\%)\end{array}$ & $\begin{array}{l}\text { Oyo }(n=80) \\
\text { Frequency }(\%)\end{array}$ & $\begin{array}{l}\text { Pooled }(n=140) \\
\text { Frequency (\%) }\end{array}$ \\
\hline 1 & Grains, white roots and tubers & $58(96.7)$ & $78(97.5)$ & $136(97.1)$ \\
2 & Legumes, nuts and seeds & $22(36.7)$ & $29(36.3)$ & $51(36.4)$ \\
3 & Dairy products (milk, yoghurt, cheese) & $3(5.0)$ & $11(13.8)$ & $14(10.0)$ \\
4 & Flesh foods & $38(63.3)$ & $53(66.3)$ & $91(65.0)$ \\
5 & Eggs & $1(1.7)$ & $6(7.5)$ & $7(5.0)$ \\
6 & Vitamins A-rich fruits and vegetables & $11(18.3)$ & $40(50.0)$ & $51(36.4)$ \\
7 & Others fruits and vegetables & $42(70.0)$ & $68(85.0)$ & $110(78.6)$ \\
& Food groups cut-off & $40(66.7)$ & $32(40.0)$ & $72(51.4)$ \\
& <4 Food groups & $20(33.3)$ & $48(60.0)$ & $68(48.6)$ \\
& $\geq 4$ Food groups & $2.90( \pm 1.20)$ & $3.56( \pm 1.27)$ & $3.28( \pm 1.28)$ \\
\hline
\end{tabular}

Field Survey Data, 2020. SD, standard deviation. children in Trinidad and Tobago (Sealey-Potts and Potts 2014) These results are consistent with findings from Savy et al. (2005); Keding et al. (2012); Herrador et al. (2015); Ochieng et al. (2017) who found that diets of children and women comprised mostly starchy staples, roots and tubers, legumes, and vegetables.

\section{The levels of agricultural commercialization of cassava farming households}

This section presents the levels of agricultural commercialization of cassava farming households in Oyo and Ogun states, South-West Nigeria. The results were computed using the CCI of each cassava farmers in the cassava farming households as specified above. The results revealed that that $9.2 \%$ and $16.1 \%$ of smallholder cassava farming households were at zero level of commercialization (non-seller) in Ogun and Oyo states respectively. About half $(49.7 \%)$ of the cassava farmers had CCI above $75 \%$ in Ogun state while $33.7 \%$ were in Oyo state. Less than $50 \%(40.1 \%)$ of the total respondents fall in the category of very high CCI. The mean household CCI of the respondents was $59.1 \%$ belonging to the category of medium-high level of commercialization (CCI III) with maximum CCI of $95.5 \%$.

This indicated that cassava farming households that did not participate in marketing of their cassava roots were low (13.4\%) while about $87 \%$ of cassava farmers participated actively in the study areas. This indicates that cassava farmers do not consume all their produce (cassava roots) but offer larger proportion for sale in open market. This is similar to the study by Hussayn et al. (2020) and Kolapo et al. (2020) who reported higher level of market participation by cassava farmers and processors in Nigeria. 
Fig. 1 Map of South-West Nigeria showing the study areas; Ogun and Oyo states. Source: maps of South-West Nigeria (Legit.ng)

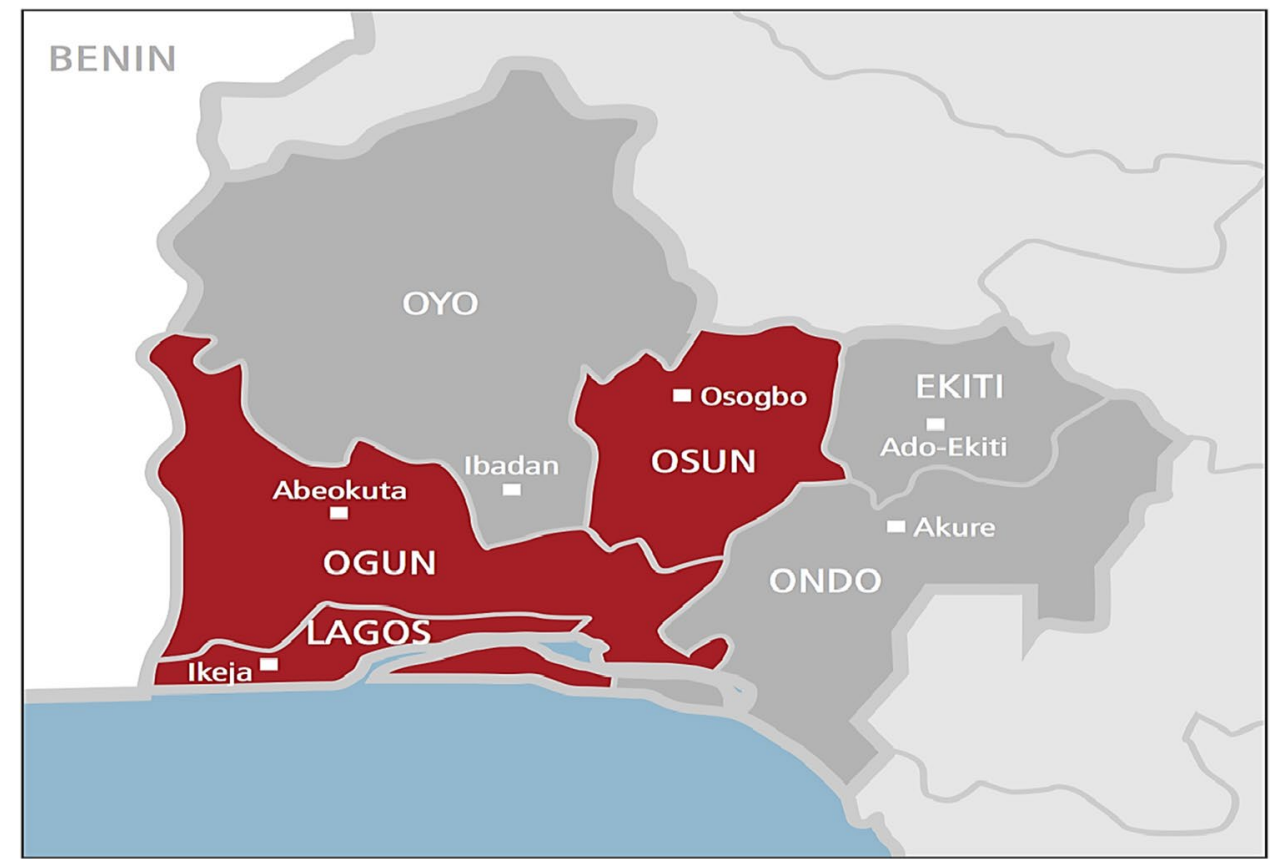

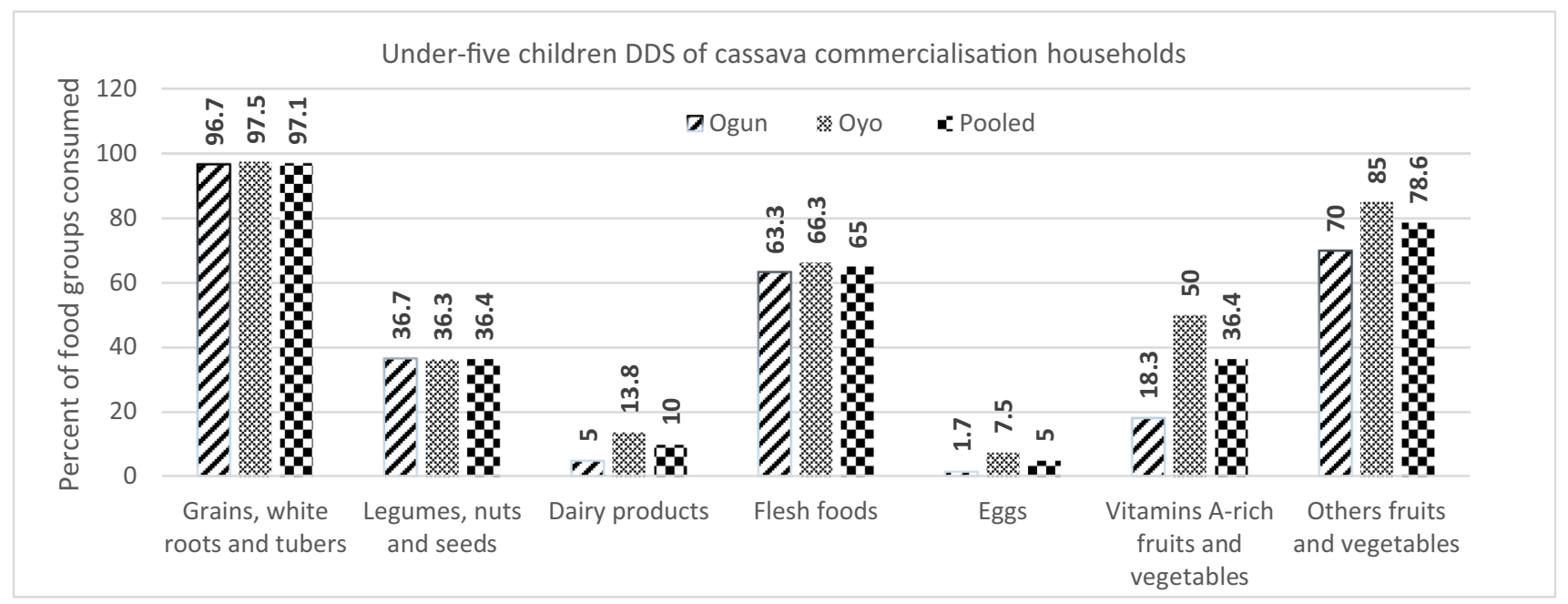

Fig. 2 Under-five children DDS of cassava commercialization households in South-West Nigeria. Source: authors' graph from field survey 2020. DDS, dietary diversity score

\section{Exploring children dietary diversity among cassava commercialization households levels}

This section brings to bear the under-five children dietary patterns belonging to the four cassava commercialization households levels (CCI I-1 V) in the Ogun and Oyo states. The results from Table 3 revealed that according to individual cassava household's CCI levels, all the under-five children in Ogun state that belong to zero commercialization households (zero level) did not meet the 4 food group benchmark while about $73 \%$ of the children in Oyo state met the
4 food groups out of 7 in 24-h recall period. Medium-high commercialization households (CCI III) in Ogun had higher percent $(68.2 \%)$ of under-five children that failed to meet up with the WHO recommended 4 food groups out of 7 while only about $30 \%$ of children in the same commercialization household (CCI III) in Oyo state did not meet the recommended 4 food groups. No under-five children were found in Ogun state low commercialization households (CCI II). The results further revealed that the highest percent $(60.7 \%)$ of children that did not meet the recommended 4 food groups in the two states belonging to the very high commercialization 
Table 3 Comparing CDDS (under-five) thresholds and CCI household levels

\begin{tabular}{lllll}
\hline CCI levels & CDDS (under-five) & $\begin{array}{l}\text { State } \\
\text { Ogun }(n=60)\end{array}$ & Oyo $(n=80)$ & Pooled $(n=140)$ \\
& & Frequency $(\%)$ & Frequency $(\%)$ & Frequency (\%) \\
\hline Zero level (non-seller) & Food groups $<4$ & $6(100)$ & $3(27.3)$ & $9(52.9)$ \\
& Food groups $\geq 4$ & - & $8(72.7)$ & $8(47.1)$ \\
& Total & $\mathbf{6 ( 1 0 0 )}$ & $\mathbf{1 1}(\mathbf{1 0 0})$ & $\mathbf{1 7}(\mathbf{1 0 0 0}$ \\
Low level & Food groups $>4$ & - & $3(30)$ & $3(30.0)$ \\
& Food groups $\geq 4$ & - & $7(70)$ & $7(70.0)$ \\
Medium-high level & Total & - & $\mathbf{1 0}(\mathbf{1 0 0})$ & $\mathbf{1 0}(\mathbf{1 0 0})$ \\
& Food groups $>4$ & $15(68.2)$ & $8(26.7)$ & $23(44.2)$ \\
& Food groups $\geq 4$ & $7(31.8)$ & $22(73.3)$ & $29(55.8)$ \\
Very high level & Total & $\mathbf{2 2}(\mathbf{1 0 0})$ & $\mathbf{3 0}(\mathbf{1 0 0})$ & $\mathbf{5 2}(\mathbf{1 0 0})$ \\
& Food groups $>4$ & $19(59.4)$ & $18(62.1)$ & $37(60.7)$ \\
& Food groups $\geq 4$ & $13(40.6)$ & $11(37.9)$ & $24(39.3)$ \\
Total & Total & $\mathbf{3 2}(\mathbf{1 0 0})$ & $\mathbf{2 9}(\mathbf{1 0 0})$ & $\mathbf{6 1}(\mathbf{1 0 0})$ \\
& Food groups $>4$ & $40(66.7)$ & $32(40.0)$ & $72(51.4)$ \\
& Food groups $\geq 4$ & $20(33.3)$ & $48(60.0)$ & $68(48.6)$ \\
& Total & $\mathbf{6 0}(\mathbf{1 0 0})$ & $\mathbf{8 0}(\mathbf{1 0 0})$ & $\mathbf{1 4 0}(\mathbf{1 0 0})$ \\
\hline
\end{tabular}

Field Survey Data, 2020. households (CCI IV) - with $59.4 \%$ under-five children in Ogun and $62.1 \%$ in Oyo states respectively.

However, results from the scatter plot (Fig. 3) between crop commercialization index (CCI) and children dietary diversity score (CDDS) revealed the existence of very weak negative association between CCI and CDDS with correlation coefficient $r=-0.1225$. This relationship shows that as CDDS increases, CCI may go down corroborating the findings (cross tabulation) in Table 3 that under-five children that belong to higher commercialization households ("VeryHigh Level) recorded the highest percentage of children that failed to meet the recommended 4 food groups out of 7 among the cassava commercializing households in the study areas. It indicated that belonging to highly commercialized households does not translate to having healthy and quality diets for the young children of cassava farming households.

\section{Under-five children's environment and health-related factors across cassava commercialization household levels}

Tables 4, 5, 6, 7, and 8 present the distribution of underfive children across cassava commercialization households according to environment and health-related factors. Among the factors considered are (i) mothers' nutrition-related knowledge, (ii) access to piped water, (iii) access to electricity, (iv) access to healthcare service, and (v) access to improved toilet in the Ogun and Oyo states.
Fig. 3 The relationship between CDDS and CCI. Source: authors' graph from field survey data 2020

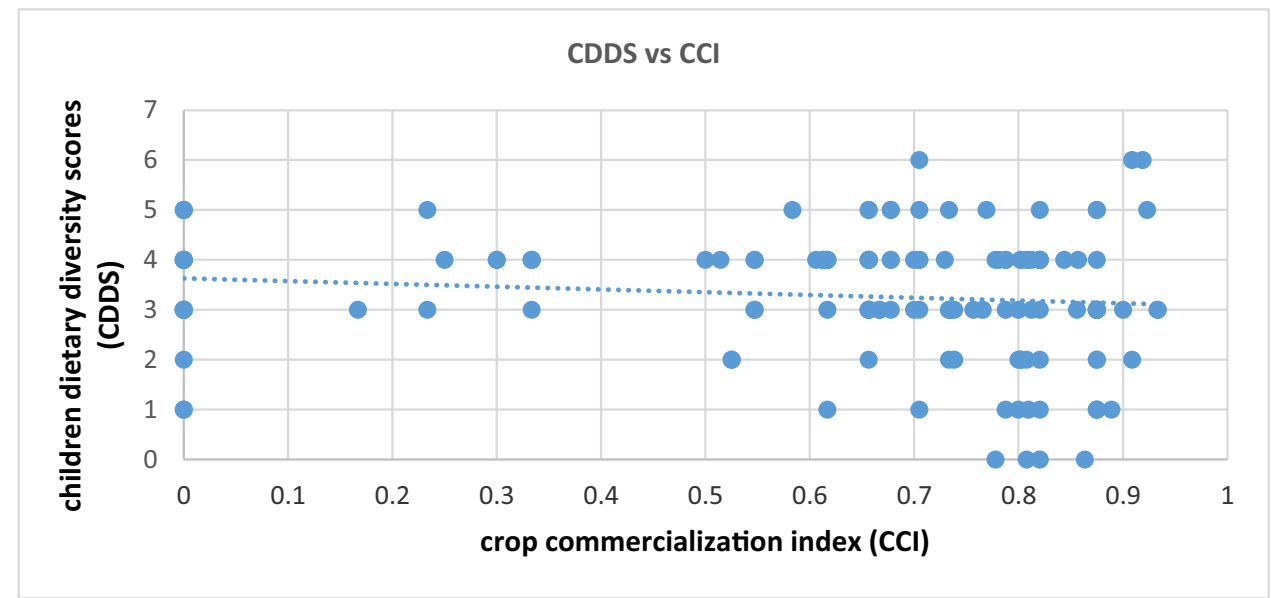


Table 4 Percent distribution of mothers' nutrition-related knowledge among cassava commercialization household levels

\begin{tabular}{|c|c|c|c|c|}
\hline \multirow[t]{3}{*}{ CCI household levels } & \multirow[t]{3}{*}{ Mothers' nutrition-related knowledge } & \multicolumn{2}{|l|}{ State } & \multirow{3}{*}{$\begin{array}{l}\text { Pooled }(n=140 \\
\text { Frequency }(\%)\end{array}$} \\
\hline & & Ogun $(n=60)$ & Oyo $(n=80)$ & \\
\hline & & Frequency $(\%)$ & Frequency $(\%)$ & \\
\hline \multirow[t]{3}{*}{ Zero level (non-seller) } & Have nutrition knowledge & $1(16.7)$ & $2(18.2)$ & $3(17.6)$ \\
\hline & No nutrition training & $5(83.3)$ & $9(81.8)$ & $14(82.4)$ \\
\hline & Total & $6(100)$ & $11(100)$ & $17(1000$ \\
\hline \multirow[t]{3}{*}{ Low level } & Have nutrition training & - & $5(50)$ & $5(50.0)$ \\
\hline & No nutrition training & - & $5(50)$ & $5(50.0)$ \\
\hline & Total & - & $10(100)$ & $10(100)$ \\
\hline \multirow[t]{3}{*}{ Medium-high level } & Have nutrition training & $2(9.1)$ & $7(23.3)$ & $9(17.3)$ \\
\hline & No nutrition training & $20(90.9)$ & $23(76.7)$ & $43(82.7)$ \\
\hline & Total & $22(100)$ & $30(100)$ & $52(100)$ \\
\hline \multirow[t]{3}{*}{ Very high level } & Have nutrition training & $6(18.8)$ & $4(13.8)$ & $10(16.4)$ \\
\hline & No nutrition training & $26(81.3)$ & $25(86.2)$ & $51(83.6)$ \\
\hline & Total & $32(100)$ & $29(100)$ & $61(100)$ \\
\hline \multirow[t]{3}{*}{ Total } & Have nutrition training & $9(15.0)$ & $18(22.5)$ & $27(19.3)$ \\
\hline & No nutrition training & $51(85.0)$ & $62(77.5)$ & $113(80.7)$ \\
\hline & Total & $60(100)$ & $80(100)$ & $140(100)$ \\
\hline
\end{tabular}

Field Survey, 2020.

Table 5 Percent distribution of access to piped water among cassava commercialization household levels

\begin{tabular}{|c|c|c|c|c|}
\hline \multirow[t]{3}{*}{ CCI household levels } & \multirow[t]{3}{*}{ Access to piped water } & \multicolumn{2}{|l|}{ State } & \multirow[t]{2}{*}{ Pooled $(n=140)$} \\
\hline & & Ogun $(n=60)$ & Oуо $(n=80)$ & \\
\hline & & Frequency $(\%)$ & Frequency $(\%)$ & Frequency $(\%)$ \\
\hline \multirow[t]{3}{*}{ Zero level (non-seller) } & Have access to piped water & $2(33.3)$ & $0(0.0)$ & $2(11.8)$ \\
\hline & No access to piped water & $4(66.7)$ & $11(100)$ & $15(88.2)$ \\
\hline & Total & $6(100)$ & $11(100)$ & $17(100)$ \\
\hline \multirow[t]{3}{*}{ Low level } & Have access to piped water & - & $0(0.0)$ & $0(0.0)$ \\
\hline & No access to piped water & - & $10(100)$ & $10(100.0)$ \\
\hline & Total & - & $10(100)$ & $10(100)$ \\
\hline \multirow[t]{3}{*}{ Medium-high level } & Have access to piped water & $8(36.4)$ & $0(0.0)$ & $8(15.4)$ \\
\hline & No access to piped water & $14(63.6)$ & $30(100)$ & $44(84.6)$ \\
\hline & Total & $22(100)$ & $30(100)$ & $52(100)$ \\
\hline \multirow[t]{3}{*}{ Very high level } & Have access to piped water & $5(15.6)$ & $0(0.0)$ & $5(8.2)$ \\
\hline & No access to piped water & $27(84.4)$ & $29(100)$ & $56(91.8)$ \\
\hline & Total & $32(100)$ & $29(100)$ & $61(100)$ \\
\hline \multirow[t]{3}{*}{ Total } & Have access to piped water & $15(25.0)$ & $0(0.0)$ & $15(10.7)$ \\
\hline & No access to piped water & $45(75.0)$ & $80(100)$ & $125(89.3)$ \\
\hline & Total & $60(100)$ & 80 (100) & $140(100)$ \\
\hline
\end{tabular}

Field Survey, 2020.
Table 4 revealed the level of nutrition-related knowledge among mothers of under-five children in the study areas. The mothers of different cassava commercialization household levels were asked if they were exposed to any nutrition knowledge such as nutrition-related subjects in schools, nutrition training programs by extension officers, or other government and non-governmental organizations, listening to nutrition-related programs on radio and television before the survey was conducted. The results (Table 4) indicated that about $82 \%$ of the mothers in zero commercialization level (CCI I) did not have any form of nutrition knowledge in the two states while it was the same in medium-high 
Table 6 Percent distribution of access to electricity among cassava commercialization household levels

\begin{tabular}{lllll}
\hline CCI household levels & Access to electricity & State & \multicolumn{2}{l}{ Pooled $(n=140)$} \\
\cline { 3 - 4 } & & Ogun $(n=60)$ & Oyo $(n=80)$ & \\
& & Frequency $(\%)$ & Frequency (\%) & Frequency (\%) \\
\hline Zero level (non-seller) & Have access to electricity & $5(83.3)$ & $0(0.0)$ & $5(29.4)$ \\
& No access to electricity & $1(16.7)$ & $11(100)$ & $12(70.6)$ \\
& Total & $\mathbf{6}(\mathbf{1 0 0})$ & $\mathbf{1 1}(\mathbf{1 0 0})$ & $\mathbf{1 7}(\mathbf{1 0 0})$ \\
Low level & Have access to electricity & - & $2(20.0)$ & $2(20.0)$ \\
& No access to electricity & - & $8(80)$ & $8(80.0)$ \\
Medium-high level & Total & - & $\mathbf{1 0}(\mathbf{1 0 0})$ & $\mathbf{1 0}(\mathbf{1 0 0})$ \\
& Have access to electricity & $16(72.7)$ & $4(13.3)$ & $20(38.5)$ \\
& No access to electricity & $6(27.3)$ & $26(86.7)$ & $32(61.5)$ \\
& Total & $\mathbf{2 2}(\mathbf{1 0 0})$ & $\mathbf{3 0}(\mathbf{1 0 0})$ & $\mathbf{5 2}(\mathbf{1 0 0})$ \\
Very high level & Have access to electricity & $16(50.0)$ & $3(10.3)$ & $19(31.1)$ \\
& No access to electricity & $16(50.0)$ & $26(89.7)$ & $42(68.9)$ \\
& Total & $\mathbf{3 2}(\mathbf{1 0 0})$ & $\mathbf{2 9}(\mathbf{1 0 0})$ & $\mathbf{6 1}(\mathbf{1 0 0})$ \\
& Have access to electricity & $37(61.7)$ & $9(11.3)$ & $46(32.9)$ \\
& No access to electricity & $23(38.3)$ & $71(88.8)$ & $94(67.1)$ \\
& Total & $\mathbf{6 0}(\mathbf{1 0 0})$ & $\mathbf{8 0}(\mathbf{1 0 0})$ & $\mathbf{1 4 0}(\mathbf{1 0 0})$ \\
\hline
\end{tabular}

Field Survey, 2020.

\begin{tabular}{lllll}
\hline CCI household levels & Access to healthcare services & State & \multicolumn{2}{l}{ Pooled $(n=140)$} \\
\cline { 3 - 4 } & & Ogun $(n=60)$ & Oyo $(n=80)$ & \\
& & Frequency $(\%)$ & Frequency $(\%)$ & Frequency $(\%)$ \\
\hline Zero level (non-seller) & Have access to healthcare & $5(83.3)$ & $3(27.3)$ & $8(47.1)$ \\
& No access to healthcare & $1(16.7)$ & $8(72.7)$ & $9(52.9)$ \\
& Total & $\mathbf{6}(\mathbf{1 0 0})$ & $\mathbf{1 1}(\mathbf{1 0 0})$ & $\mathbf{1 7}(\mathbf{1 0 0})$ \\
Low level & Have access to healthcare & - & $7(70.0)$ & $7(70.0)$ \\
& No access to healthcare & - & $3(30)$ & $3(30.0)$ \\
Medium-high level & Total & - & $\mathbf{1 0}(\mathbf{1 0 0})$ & $\mathbf{1 0}(\mathbf{1 0 0})$ \\
& Have access to healthcare & $20(90.9)$ & $17(56.7)$ & $37(71.2)$ \\
& No access to healthcare & $2(9.1)$ & $13(43.3)$ & $15(28.8)$ \\
& Total & $\mathbf{2 2 ( 1 0 0 )}$ & $\mathbf{3 0}(\mathbf{1 0 0})$ & $\mathbf{5 2}(\mathbf{1 0 0})$ \\
Very high level & Have access to healthcare & $18(56.3)$ & $10(34.5)$ & $28(45.9)$ \\
& No access to healthcare & $14(43.8)$ & $19(65.5)$ & $33(54.1)$ \\
& Total & $\mathbf{3 2}(\mathbf{1 0 0})$ & $\mathbf{2 9}(\mathbf{1 0 0})$ & $\mathbf{6 1}(\mathbf{1 0 0})$ \\
& Have access to healthcare & $43(71.7)$ & $37(46.3)$ & $80(57.1)$ \\
& No access to healthcare & $17(28.3)$ & $43(53.8)$ & $60(42.9)$ \\
& Total & $\mathbf{6 0}(\mathbf{1 0 0})$ & $\mathbf{8 0}(\mathbf{1 0 0})$ & $\mathbf{1 4 0}(\mathbf{1 0 0})$ \\
\hline
\end{tabular}

Field Survey, 2020.
Table 7 Percent distribution of access to healthcare services among cassava commercialization household levels commercialization households (CCI III) where just $17 \%$ of the mothers had nutrition-related knowledge that can help in improving the nutrition and households dietary patterns. Generally, the results revealed that about $81 \%$ of the mothers in the four cassava commercialization household levels in rural settings of the two states (Ogun, 85.0\%; Oyo, 77.5\%) did not have any form of nutrition knowledge that can help in improving the nutrition and healthy living of the children and other members of the households. This similar to the studies by Fadare et al. (2019) who found low level of mothers' nutrition-related knowledge among rural households in Nigeria. Moreover, other studies found positive association between mothers' educational background (in order to assess healthcare services and comprehend health-related 
Table 8 Percent distribution of access to improved toilet among cassava commercialization household levels

\begin{tabular}{|c|c|c|c|c|}
\hline \multirow[t]{3}{*}{ CCI household levels } & \multirow[t]{3}{*}{ Access to improved toilet } & \multicolumn{2}{|l|}{ State } & \multirow[t]{2}{*}{ Pooled $(n=140)$} \\
\hline & & Ogun $(n=60)$ & Oyo $(n=80)$ & \\
\hline & & Frequency $(\%)$ & Frequency (\%) & Frequency (\%) \\
\hline \multirow[t]{3}{*}{ Zero level (non-seller) } & Have access to improved toilet & $3(50.0)$ & $0(0.0)$ & $3(17.6)$ \\
\hline & No access to improved toilet & $3(50.0)$ & $11(100)$ & $14(82.4)$ \\
\hline & Total & $6(100)$ & $11(100)$ & $17(100)$ \\
\hline \multirow[t]{3}{*}{ Low level } & Have access to improved toilet & - & $1(10.0)$ & $1(10.0)$ \\
\hline & No access to improved toilet & - & $9(90)$ & $9(90.0)$ \\
\hline & Total & - & $10(100)$ & $10(100)$ \\
\hline \multirow[t]{3}{*}{ Medium-high level } & Have access to improved toilet & $8(36.4)$ & $4(13.3)$ & $12(23.1)$ \\
\hline & No access to improved toilet & $14(63.6)$ & $26(86.7)$ & $40(76.9)$ \\
\hline & Total & $22(100)$ & $30(100)$ & $52(100)$ \\
\hline \multirow[t]{3}{*}{ Very high level } & Have access to improved toilet & $13(40.6)$ & $3(10.3)$ & $16(26.2)$ \\
\hline & No access to improved toilet & $19(59.4)$ & $26(89.7)$ & $45(73.8)$ \\
\hline & Total & $32(100)$ & $29(100)$ & $61(100)$ \\
\hline \multirow[t]{3}{*}{ Total } & Have access to improved toilet & $24(40.0)$ & $8(10.0)$ & $32(22.9)$ \\
\hline & No access to improved toilet & $36(60.0)$ & $72(90.0)$ & $108(77.1)$ \\
\hline & Total & $60(100)$ & 80 (100) & $140(100)$ \\
\hline
\end{tabular}

Field Survey, 2020. messages) and children nutrition (including higher dietary diversity) in other developing economies (Abuya et al. 2011; Frempong and Annim 2017; Rakotonirainy et al. 2018; Custodio et al. 2019).

Table 5 showed the level of access to piped water among cassava commercializing households in Ogun and Oyo states. The result indicated that about $88 \%$ of the cassava commercialization household belonging to zero level (CCI I) did not have access to piped water in the two states (Ogun, $66.7 \%$ and Oyo, $100 \%$ ), while only $15.4 \%$ had access to piped water in medium-high commercialization households (CCI III) in the two states. The result further revealed that very high commercialization households (CCI IV) had the highest percentage $(91.8 \%)$ of households with no access to piped water among the four cassava commercialization household levels in the two states (Ogun, 84.4\% and Oyo, $100 \%$ ). Generally, only about $11 \%$ of the cassava commercialization households had access to potable source of drinking water in the two states (Ogun, 25.0\% and Oyo 0\%). This is abysmally lower than the national average $(58.4 \%)$ recorded in the 2018 for rural households in the country (NPC \& ICF 2019). This result is similar to the findings from South Africa (but with higher access to piped water), where it indicated that about $45 \%$ of households in South Africa were able to access piped water in 2019 (Omotayo et al. 2021).

Table 6 revealed the level of access to electricity across the four categories of cassava commercializing households in the study areas. The result showed that only about $29 \%$ of the cassava commercialization household belonging to zero level (CCI I) had access to electricity in the two states while about $69 \%$ do not have access to electricity in very-high commercialization households (CCI IV) in the two states (Ogun, 50.0\% and Oyo, 89.7\%). Table 6 further indicated that about $67 \%$ of all the four categories of cassava commercialization households in the two states were with no access to electricity (Ogun, 38.3\%\% and Oyo, 88.8\%). The percentage of cassava commercialization households in Oyo state (having under-five children) with no access to electricity was more than twice the percentage of those in Ogun state. This result is still lower $(32.9 \%)$ than the national average $(38.9 \%)$ of rural households with access to electricity revealed in the 2018 NDHS (NPC and ICF 2019). This may not be unconnected to the fact that more rural farming households in Ogun were connected to the national grid which gave them more access to electricity than those in Oyo state. Moreover, considering Africa's electricity index which revealed that Nigeria's electricity index score (score/100) fluctuate between 1.95 in 2003 and 2.72 in 2020 (AfDB 2013; 2020). Access to electricity tends to improve the living condition of the rural households. It also provides access to nutritionrelated information from mass media such as television and radio that can help improve the dietary patterns and diet quality of the young children and that of the entire cassava commercialization households.

Table 7 indicated the level of access to healthcare service across the four categories of cassava commercializing households in Ogun and Oyo state, South-West Nigeria. The result revealed that about $47 \%$ of the cassava commercialization household belonging to zero level (CCI I) had access 
to healthcare services in the two states while about $71 \%$ of the medium-high commercialization households had access to healthcare services in the two states (Ogun, 90.9\% and Oyo, 56.7\%) and also recorded the highest percentage of households with access to healthcare among the four cassava commercializing households in the study areas. Table 7 further indicated that about $57 \%$ of all the four categories of cassava commercialization households in the two states had access to healthcare (Ogun, 71.7\% and Oyo, 46.3\%). Considering access to healthcare in the two states, higher percent $(71.7 \%)$ of cassava farming households in Ogun state had access to healthcare that those in Oyo state (46.3\%). This result revealed better availability of rural healthcare services in Ogun state than that of Oyo state.

Table 8 indicated the level of access to improve toilet among cassava commercialization household levels in the study areas (Ogun and Oyo states). The result showed that only about $18 \%$ of the cassava commercialization household belonging to zero level (CCI I) had access to improved toilet while less than $25 \%(23.1 \%)$ of the households in medium-high commercialization level had access to improved toilet in the two states. Table 8 further indicated that $77.1 \%$ of all the four cassava commercialization household levels did not have access to improved toilet in the study areas (Ogun, 60.0\% and Oyo, 90.0\%). This result is lower
(22.9\%) than the national average of about $39 \%$. The Nigeria DHS 2018 revealed that only $39.1 \%$ of rural households had access to improved toilet and about $33 \%$ of rural households use open defecation (NPC and ICF 2019). According to United Nations Children's Fund (UNICEF), Nigeria is ranked second globally with 38 million people practicing open defecation while West and Central Africa accounted for about 24\% of global open defecation (UNICEF 2021). Open defecation is believed to aggravate the prevalence of malnutrition and diarrheal disease incidence mostly in young children and it is a leading cause of child deaths in Africa (UNICEF 2021; Omotayo et al. 2021).

\section{Determinants of under-five children dietary diversity}

Logit regression results of the factors influencing under-five dietary diversity among cassava farming households are presented in Table 9. As indicated above, logit regression was used to regress children dietary diversity against some sets of explanatory variables such as household and child-related, environment, and health-related variables. The dependent variable is a dummy, 1 if child failed to meet the WHO recommended 4 food groups out of 7 and zero otherwise. The results indicated that the log-likelihood ratio is -77.86 with
Table 9 Results of the logistic regression of children dietary diversity

\begin{tabular}{lllll}
\hline Variables & Estimated values & $\begin{array}{l}\text { Robust stand- } \\
\text { ard error }\end{array}$ & $P>|z|$ & Marginal effects \\
\hline Child age (months) & $0.0356^{* * *}$ & 0.0119 & 0.003 & 0.0088 \\
+ Child gender & $0.8307^{*}$ & 0.4695 & 0.077 & 0.2041 \\
Mothers' age & $0.0505^{* *}$ & 0.0243 & 0.038 & 0.0126 \\
Mothers' year of schooling & $0.1001^{*}$ & 0.0564 & 0.076 & 0.0250 \\
Household Size & -0.0107 & 0.0935 & 0.909 & -0.0027 \\
Farm Size & 0.2226 & 0.3791 & 0.557 & 0.0556 \\
Farm Income & $-1.39 \mathrm{e}-06$ & $2.69 \mathrm{e}-06$ & 0.606 & $-3.46 \mathrm{e}-07$ \\
Nonfarm Income & $3.96 \mathrm{e}-06$ & $3.76 \mathrm{e}-06$ & 0.291 & $9.87 \mathrm{e}-07$ \\
Distance (farm to market) & $-0.1483^{* *}$ & 0.0573 & 0.010 & -0.0370 \\
Food expenditure & $-0.00006^{* *}$ & 0.00003 & 0.030 & -0.00002 \\
+ Mothers' nutrition knowledge & -0.0353 & 0.5469 & 0.948 & -0.0088 \\
+ Access to healthcare & $-1.0501^{*}$ & 0.5415 & 0.052 & -0.2566 \\
+ Access to electricity & 0.1670 & 0.6151 & 0.786 & -0.0417 \\
+ Access to toilet & -0.4911 & 0.5731 & 0.391 & -0.1207 \\
Crop sold ratio & 0.0844 & 0.8321 & 0.919 & 0.0211 \\
Constant & -1.1798 & 1.2531 & 0.346 & \\
\hline
\end{tabular}

(+) Represent dummy variable $(0$ or 1$)$. $* * *$ Significance at $1 \%$ level, **significance at $5 \%$ level, *significance at $10 \%$ level.

Number of observation $=140$.

Wald $\operatorname{chi}^{2}(15)=34.25$.

Prob $>$ chi $^{2}=0.0031$.

Log pseudo likelihood $=-77.862423$.

Pseudo $R^{2}=0.1972$. 
Chi-square probability $\left(\operatorname{Prob}>\mathrm{chi}^{2}=0.0031\right)$ significant at $1 \%$ level, suggesting that the model of good fit. The results in Table 9 revealed that age (months) and mothers' age of cassava farming households in the study areas of Ogun and Oyo states are both significant and positively influence the dietary diversity of the under-five children. The marginal effect coefficient shows that a unit increase in age of child is expected to lead to $0.0088(0.85 \%)$ increases in the probability of under-five children meeting up the WHO recommended DDS of 4 food groups out of 7 per day. This implies that as the child grows older, the probability of meeting the recommended DDS of 4 food groups per day becomes higher. This is similar to Rakotonirainy et al. (2018) who found that young children mostly consume relatively non varying diets than older children in Madagascar. Also, Custodio et al. (2019) opined that age increase in young children is significantly associated to minimum CDDS. The results marginal effect coefficient of mother's age showed that a unit increase in mother's age will increase the likelihood of a child consuming diverse diets (meeting the recommended CDDS) by $0.0126(1.26 \%)$ when all other factors are held constant. This suggests that the likelihood of not meeting the recommended 4 food groups per day among under-five children reduces as the mother advances in age. This may be connected to the fact that older mothers have more knowledge and experience (informal education) on traditional food preparation that can improve nutrition and wellbeing of the household especially young children.

Distance to market and food expenditure are both significant $(p<0.05)$ but have negative relationship with the children dietary diversity. The marginal effect coefficient of 0.0370 (distance to market) suggests that a unit increase in distance from farm to market $(\mathrm{Km})$ will make the probability of under-five children consuming the recommended 4 food groups go down by $3.9 \%$. The implication of this is that, the farther the distance to the market, the more difficult it is for the children to meet the recommended CDDS. Also, if food expenditure increases by one percent point, the probability of children meeting the recommended 4 food groups per day reduces by $0.002 \%$. This may be possible if the choice of food consumed in the households were not diverse but monotonous in nature especially energy-dense food (mostly carbohydrates), will make it difficult to meet the recommended 4 food groups out of 7 per day.

Moreover, mother's education is significant at $10 \%$ level. A unit increase in educational level of a mother of an underfive child will increase the likelihood of a child consuming diverse diets and meeting the recommended DDS by 0.0250 (2.5\%) when other factors are held constant. This is consistent with Aemro et al. (2011); Senarath et al. (2012); Rakotonirainy et al. (2018) who posited that low educational level of mothers in households increased the likelihood of the children having a low dietary diversity score. The education of the parents, especially mothers is very vital in determining how diverse the diets of their household would be especially the young children (Custodio et al. 2019).

Furthermore, access to healthcare services is significant but has a negative influence on under-five children DDS. A unit increase in access to healthcare reduces the probability of under-five children meeting the recommended DDS by $25.6 \%$. This result is contrary to a priori expectation that the more access households have to healthcare services the better their health status. This may be due to the fact that most of the healthcare centers in the study areas are non-existent and those available are ill-equipped with no healthcare personnel to attend them when healthcare services are needed urgently. This is contrary to the findings by $\mathrm{Na}$ et al. (2017); (2018) who posited that access to health and nutrition services are associated with children dietary diversity.

The result also revealed that household commercialization levels (crop sold ratio) did not significantly influence children dietary diversity in the study areas. This indicated that levels (CCI I-VI) of commercialization among cassava farming households may not influence the dietary diversity or diet quality of young children and also the entire farm households. Other studies that found similar results (but with women) that CCI household levels did not significantly influence minimum dietary diversity for women (MDD-W) in Ogun and Oyo state, Nigeria (Otekunrin and Otekunrin 2021a).

\section{The study limitations}

The study adopted only 24-h recall period for assessing of the dietary diversity of the rural cassava farming households in the study areas. The study relied solely on the ability of the members of the farming households to remember and the correctness of the type of food consumed in that recall period. Also, this study employed only under-five children of rural crop farmers (only cassava farmers) with no consideration for under-five children from rural livestock farming households in the study areas. The study was carried out among rural smallholder cassava farming households having less than 5 ha of farmland while farmers/farming households with more than 5 ha of farmlands were excluded which may give different results.

The results from Ogun and Oyo states (South-West) in this study may not be generalized for all rural farming households from other geo-political zones in Nigeria.

\section{Future research areas}

Future studies aimed at assessing the dietary diversity of under-five children of farming households may be carried out in other geo-political zones (South-South, North-Central, South-East, North-West, and North-East) of Nigeria. 
Moreover, other studies on dietary diversity of other members of the farming households such as young children (aged 5-9 years), adolescents (10-19 years), women of childbearing age, and men are also needed to assess the dietary patterns of the farming households.

\section{Conclusion and recommendations}

Based on the findings of this study, majority of under-five children consumed grains, with roots and tubers while less than $40 \%$ consumed legumes in both Ogun and Oyo states. In the two states, about $49 \%$ met the recommended minimum cut-off point of 4 food groups with dietary diversity mean score of 3.28. The distribution of under-five children across cassava commercialized households according to environment and health-related factors revealed that about $81 \%$ of the mothers did not have any form of nutrition-related knowledge while $77 \%$ of the four cassava commercialization household levels did not have access to improved toilet in the two states. The logit regression analysis indicated that child's age, mothers' age, distance to farm, and food expenditure were among the significant determinants of under-five children dietary diversity. The study revealed the existence of very weak negative association between CCI and CDDS which corroborated the findings that under-five children that belong to higher commercialization households ("Very-High Level) recorded the highest percentage of children that failed to meet the recommended 4 food groups out of 7 among the cassava commercializing households in the study areas. Therefore, based on the findings, the study recommends that stakeholders should facilitate adequate nutrition training/orientation for members of farming households especially those saddled with the responsibility of households' food preparation in order to improve their diet quality. Also, there is need for government and non-governmental organizations (NGOs) intervention in the provision of rural infrastructure development such as access road network, functional healthcare centers, public conveniences (improved toilet facilities), and functional piped water facilities to improve the living condition of the rural farming households.

Acknowledgements All authors sincerely appreciate all farming household members that participated in the survey. Authors also appreciate the reviewers for their invaluable comments which have led to significant improvement in the paper.

Author contribution Conceptualization, O.A.O (first author); methodology, O.A.O, I.A.A, R.A.S, and O.O.O, O.A., writing-original draft preparation, O.A.O (first author), O.A.O, I.A.A, R.A.S, and O.O.O., writing-reviewing and editing, O.A.O (first author), O.A.O, I.A.A, R.A.S, and O.O.O. All authors have read and agreed to the published version of the manuscript.
Data availability The data that support the findings of this study are available upon reasonable request from the authors.

\section{Declarations}

Ethical approval and consent to participate The study was approved by the Department of Agricultural Economics and Farm Management Review Board of Federal University of Agriculture, Abeokuta (FUNAAB), Nigeria. Also, the Oyo State Ethics Review Committee of the Ministry of Health, Department of Planning, Research \& Statistics approved this study with Reference Number: AD13/479/4420 . Informed consent was obtained from the respondents before the survey was carried out and respondent data are fully anonymized.

Competing interests The authors declare no competing interests.

\section{References}

Abuya B, Onsomu E, Kimani J, Moore D (2011) Influence of maternal education on child immunization and stunting in Kenya. Matern Child Health J 15:1389-1399

Aemro M, Mesele M, Birhanu Z (2011) Dietary diversity and meal frequency practices among infant and young children aged 6-23 months in Ethiopia: a secondary analysis of Ethiopian demographic and health survey. J Nutr Metab 782931.

Africa Development Bank (AfDB) (2013) The Africa Infrastructure Development Index (AIDI). 1-26.

Africa Development Bank (AfDB) (2020) The Africa Infrastructure Development Index (AIDI) 2020. 1-19.

Agricultural Policy Research in Africa (APRA). (2018). What is agricultural commercialization: who benefits and how do we measure it? Issue 1, 1-6.

Akerele D, Sanusi RA, Fadare OA, Ashaolu OF (2017) Factors influencing nutritional adequacy among rural households in Nigeria: how does dietary diversity stand among influencers? Ecol Food Nutr 56(2):187-203

Ayinde IA, Otekunrin OA, Akinbode SO, Otekunrin OA (2020) Food security in Nigeria: impetus for growth and development. J Agric Econ Rural Dev 6(2):808-820

Azadbahkt L, Esmailzader A (2012) Dietary patterns and attention deficit hyperactivity disorder among Iranian children. Nutrition 28(3):242-249

Carletto C, Corral P, Guelfi A (2017) Agricultural commercialization and nutrition revisited: empirical evidence from three African countries. Food Policy 67:106-118

Custodio E, Herrador Z, Nkunzimana T, Węziak-Białowolska D, Perez-Hoyos A, Kayitakire F (2019) Children's dietary diversity and related factors in Rwanda and Burundi: a multilevel analysis using 2010 Demographic and Health Surveys. PLoS ONE 14(10):e0223237

Donati M, Menozzi D, Zighetti C, Rosi A, Zinetti A, Scazzina F (2016) Towards a sustainable diet combining economic, environmental and nutritional objectives. Appetite 106:48-57

Drewnowski A (2014) Healthy diets for a healthy planet. Am J Clin Nutr 99(6):1284-1285

Ekesa BN, Blomme G, Garming H (2011) Dietary diversity and nutritional status of preschool children from MUSA-dependent households in GItega (Burundi) and Butembo (Democratic Republic of Congo). Afr J Food Agric Nutr Dev 11:4896-4911

European Public Health Association (EUPHA) (2017) Healthy and sustainable diets for European countries. Retrieved from https:// 
eupha.org/repository/advocacy/EUPHA_report_on_healthy_ and_sustainable_diets_20-05-2017.pdf. Accessed 27 Jul 2021

Fadare O, Amare M, Mavrotas G, Akerele D, Ogunniyi A (2019) Mother's nutrition-related knowledge and child nutrition outcomes: empirical evidence from Nigeria. PLoS ONE 14(2):e0212775

Fanzo J (2019) Healthy and sustainable diets and food systems: the key to achieving sustainable development goal 2? Food Ethics $4: 159-174$

FAO, IFAD, UNICEF, WFP, WHO (2020) The State of Food Security and Nutrition in the World 2020. Transforming food systems for affordable healthy diets. FAO, Rome.

FAO, IFAD, UNICEF, WFP, WHO (2021) The State of Food Security and Nutrition in the World 2021. Transforming food systems for food security, improved nutrition and affordable healthy diets for all. Rome, FAO. Rome.

FAOSTAT (2021) Food and Agriculture Organisation of the United Nations Statistical Database; Statistical Division; FAO: Rome, Italy.

Find Latitude and Longitude (2021). https://www.findlatitudeand longitude.com/I/southwest+nigeria+africa/501431/ accessed on 29 September 2021.

Frempong RB, Annim SK (2017) Dietary diversity and child malnutrition in Ghana. Heliyon, 3, e00298.

Garnett T (2016) Plating up solutions. Science 353(6305):1202-1204

Garnett T (2017) Livestock and climate change. The meat crisis. Routledge, London, pp 31-51

Global Panel (Global Panel on Agriculture and Food Systems for Nutrition) (2016) Food systems and diets: facing the challenges of the 21st century. Foresight Report, London. https://www. glopan.org/sites/default/files/Downloads/Foresight\%20Report. pdf. Accessed 26 Jul 2021

Gujarati DN, Porter DC. Basic Econometrics Fifth edition 2009

Herrador Z, Jesus P, Sordo L, Gadisa E, Moreno J, Benito A et al (2015) Low dietary diversity and intake of animal source foods among school aged children in Libo Kemkem and Fogera districts, Ethiopia. PLoS ONE 10(7):e0133435

Hilbruner C, Egan R (2008) Seasonality, household food security and nutritional status in Dinjpur, Bangladesh. Food Nutr Bull 29(3):221-231

Hussayn JA, Gulak DM, Aboaba KO, Keshinro OO (2020) Effects of agricultural commercialization on poverty status of smallholder cassava farming households in Oyo State. Sci Papers, Ser Manag. Econom. Eng. Agric. Rural Dev. 20(4): 255-266.

International Food Policy Research Institute (IFPRI), 2016International Food Policy Research Institute (IFPRI) (2016) Global food policy report. Washington, DC: International Food Policy Research Institute.

Johns T, Eyzaguirre PB (2007) Biofortification, biodiversity and diet: a search for complimentary applications against poverty and malnutrition. Food Policy 32(1):1-24

Keding GB, Msuya JM, Maass BL, Krawinkel MB (2012) Relating dietary diversity and food variety scores to vegetable production and socio-economic status of women in rural Tanzania. Food Secur 4(1): 129-140

Kennedy G, Berado A, Papavero C, Horjus P, Ballard T, Dop M (2010) Proxy measures of household food consumption for food security assessment and surveillance, comparison of the household dietary diversity and food consumption scores. J Public Health Nutr 13(12):2010-2018

Kennedy G, Keding G, Evang E, Giulia RN, Scheerer L (2017) Nutrition baseline survey summary report. Global Programme Food and Nutrition Security, Enhanced Resilience.

Kolapo A, Yusuf OJ, Abdulmumin MO (2020) Market participation and food security status of bio-fortified cassava processors in South Western Nigeria. Int J Sustain Agric Res 7(3):174-184
Lawal BO, Samuel FO (2010) Determinant of nutritional status of children in farming households in Oyo State, Nigeria. Afr J Food Agric Nutr Dev 10(10):4235-4253

Mirmiran P, Azadbaht L, Azizi F (2006) Dietary diversity within food groups: an indicator of specific nutrient adequacy in tehranian women. J Am Coll Nutr 25(4):354-361

Map of South West Nigeria. https://www.legit.ng/1117167-southweststates-nigeria.html. Accessed 5 Aug 2021

Maps of World (2021). https://wwww.mapsofworld.com/lat_long/niger ia-lat-long.html Accessed on 5 August 2021

Na M, Aguayo VM, Arimond M, Mustaphi P (2018) Stewart CP (2018) Predictors of complementary feeding practicesin Afghanistan: analysis of the 2015 Demographic and Health Survey. Matern Child Nutr. 14:e12696

Na M, Aguayo VM, Arimond M, Stewart CP (2017) Risk factors of poor complementary feeding practices in Pakistani children aged 6-23 months: a multilevel analysis of the Demographic and Health Survey 2012-2013. Matern Child Nutr 13:e12463

National Population Commission (NPC) [Nigeria], ICF (2019). Nigeria demographic and health survey 2018. Abuja, Nigeria and Rockville, Maryland, USA: NPC and ICF.

Obayelu OA, Osho FO (2020) How diverse are the diets of low-income urban households in Nigeria? J Agric Food Res 2:1-8

Ochieng J, Afari-Sefa V, Lukumay PJ, Dubois T (2017) Determinants of dietary diversity and the potential role of men in improving household nutrition in Tanzania. PLoS ONE 12(12):e0189022

Okezie C, Nwosu A (2007) The effect of agricultural commercialization on the nutritional status of cocoa growing households in Ikwuano LGA of Abia State Nigeria. Int J Agric Rural Dev 9:12-15

Omotayo AO, Olagunju KO, Omotoso AB, Ogunniyi AI, Otekunrin OA, Daud AS (2021) Clean water, sanitation and under-five children diarrhea incidence: empirical evidence from the South Africa's general household survey. Environ Sci Pollut Res https:// doi.org/10.1007/s11356-021-15182-w

Opondo FA, Dannenberg P, Willkomm M (2017) Characterization of the levels of cassava commercialization among smallholder farmers in Kenya: a multinomial regression approach. Afr J Agric Res 12(41):3024-3036

Otekunrin OA, Sawicka B (2019) Cassava, a 21st century crop: how can Nigeria harness its enormous trade potential? Acta Sci Agric 3(8):194-202

Otekunrin OA, Momoh S, Ayinde IA (2019a) Smallholders' farmers' market participation: concepts and methodological approaches from sub-Saharan Africa. Curr Agric Res 7(2):139-157

Otekunrin OA, Otekunrin OA, Momoh S, Ayinde IA (2019b) How far has Africa gone in achieving the zero hunger target? Evidence from Nigeria. Glob Food Secur 22:1-12

Otekunrin OA, Momoh S, Ayinde IA, Otekunrin OA (2019) How far has Africa gone in achieving the sustainable development goals? Exploring the African dataset. Data Brief 27:104647

Otekunrin OA, Otekunrin OA, Fasina FO, Omotayo AO, Akram M (2020) Assessing the zero hunger target readiness in Africa in the face of COVID-19 pandemic. Caraka Tani: J Sustain Agric 35(2):213-227

Otekunrin OA, Otekunrin OA, Sawicka B, Ayinde IA (2020b) Three decades of fighting against hunger in Africa: progress, challenges and opportunities. World Nutrition 11(3):86-111

Otekunrin OA, Otekunrin OA (2020) COVID-19 and hunger in Africa: a crisis within a crisis. In Proceeding of the 6th International Conference on Food Science and Technology, Vienna, Austria, 16-17 October 2020; 27-28.

Otekunrin OA, Otekunrin OA (2021a) Dietary diversity choices of women: evidence from cassava farming households in Nigeria. Arch Curr Res Int 21(4):11-22 
Otekunrin OA, Otekunrin OA (2021b) Healthy and Sustainable diets: implications for achieving SDG2. In: Leal Filho W., Azul A.M., Brandli L., Özuyar P.G \& Wall T. (eds) Zero Hunger. Encyclopedia of the UN Sustainable Development Goals. Springer, Cham.

Otekunrin OA (2021) Is Africa ready for the SDG 2 (Zero Hunger) target by 2030? Curr Agric Res J 9(1):1-3

Otekunrin OA, Fasina FO, Omotayo AO, Otekunrin OA, Akram M (2021) COVID-19 in Nigeria: why continuous spike in cases? Asian Pac J Trop Med 14(1):1-4

Rakotonirainy NH, Razafindratovo V, Remonja CR, Rasoloarijaona R, Piola P, Raharintsoa C, Randremanana RV (2018) Dietary diversity of 6- to 59-month-old children in rural areas of Moramanga and Morondava districts. Madagascar. PLoS ONE 13(7):e0200235

SAHEL (2016). Cassava: a staple Crop in Nigeria. (2016): 13.

Savy M, Martin-Prevel Y, Sawadogo P, Kameli Y, Delpeuch F (2005) Use of variety/diversity scores for diet quality measurement: relation with nutritional status of women in a rural area in Burkina Faso. Eur J Clin Nutr 59(3):703-716

Sealey-Potts C, Potts AC (2014) An assessment of dietary diversity and nutritional status of preschool children. Afr J Nutr Food Sci 2(7): 1040

Senarath U, Agho K, Akram DE, Godakandage SS, Hazir T, Jayawickrama H, Joshi N, Kabir I, Khanam M, Patel A, Pusdekar Y, Siriwardena RSK, I, Tiwari K., Dibley MJ, (2012) Comparisons of complementary feeding indicators and associated factors in children aged 6-23 months across five South Asian countries. Matern Child Nutr 8(Suppl 1):89-106

Shively G, Sununtnasuk C (2015) Agricultural diversity and child stunting in Nepal. J Dev Stud 51(8):1078-1096

Steyn N, Nel J, Nantel G, Kennedy G, Labadarrios D (2006) Food variety and dietary diversity scores in children: are they good indicators of dietary adequacy? Public Health Nutr 9:644-650

Steyn NP, Nel J, Labadarios D, Maunder EMW, Kruger HS (2014) Which dietary diversity indicator is best to assess micronutrient adequacy in children 1 to $9 \mathrm{y}$ ? Nutrition 30(1):55-60

Strasberg, P., Jayne, T., Yamano, T., Nyoro, J.K., Karanja, D.D and Strauss, J. (1999). Effects of agricultural commercialization on food crop input use and productivity in Kenya, policy synthesis for USAID - Africa Bureau Office of Sustainable Development 41, East Lansing MI: Michigan State University 1999.
United Nations Children's Fund (UNICEF) 2021 Young people rally to put an end to open defecation in West and Central Africa. Retrieved at: https://www.unicef.org/nigeria/press-release/youngpeople-rally-put-end-open-defecation-west-and-central-africa. Accessed 3 Aug 2021

Ukegbu PO, Ogu VC (2017) Assessment of dietary diversity score, nutritional status and socio-demograhic characteristics of underfive children in some rural areas of Imo State. Nigeria Mal J Nutr 23(3):425-435

United Nations General Assembly (2015) Transforming our world: the 2030 agenda for sustainable development: sustainable development knowledge platform. https://sustainabledevelopment.un.org/ post2015/transformingourworld Accessed on 31 July 2021

von Grebmer K., Bernstein J, Mukerji R, Patterson F, Wiemers M, Ni Cheilieachair R, Foley C, Gitter S., Ekstrom K, Fritschel H (2019) 2019 Global hunger index: the challenge of hunger and climate. Bonn: Welthungerhilfe; and Dublin: Concern Worldwide.

World Health Organization (WHO) (2007) Indicators for assessing infants and young children feeding practices: conclusions of a consensus meeting held. Washington DC: World Health Organization.

World Health Organizations of the United Nations (WHO) (2013) Strategy on diet, physical activity and health.

Willett W, Rockström J, Loken B, Springmann M, Lang T, Vermeulen S, Garnett T, Tilman D, DeClerck F, Wood M, Jonell M, Clark M, Gordon LJ, Fanzo J, Hawkes C, Zurayk R, Rivera JA, De Vries W, Sibanda LM, Afshin A, Chaudhary A, Herrero M, Agustina R, Branca F, Lartey A, Fan S, Crona B, Fox E, Bignet V, Troell M, Lindahl T, Singh S, Cornell SE, Reddy KS, Narain S, Nishtar S, Murray CJL (2019) Food in the Anthropocene: the EAT-Lancet Commission on healthy diets from sustainable food systems. The Lancet 393(10170):447-492

Publisher's note Springer Nature remains neutral with regard to jurisdictional claims in published maps and institutional affiliations. 